\title{
Sistem informasi Data Poin Pelanggaran Siswa Menggunakan Metode Prototyping Berbasis Web Pada SMA Negeri 10 Kota
}

\author{
Rani Hormati ${ }^{1}$, Sartina Yusuf ${ }^{2}$, Muhdar Abdurahman ${ }^{3}$ \\ 1,2,3 Program Studi Manajemen Informatika \\ ${ }^{1,2}$ Politeknik Sains dan Teknologi Wiratama Maluku Utara \\ ${ }^{3}$ Akademi Ilmu Komputer Ternate \\ ranihormati@gmail.com
}

\begin{abstract}
Abstrak
Sekolah SMA Negeri 10 Kota Ternate terletak di Jln.Ki Hajar Dewantara, Kelurahan Takoma, Kecamatan Kota Ternate Tengah. Poin Pelanggaran Siswa pada SMA Negeri 10 Kota Ternate saat ini masih dicatat manual dan penyimpanan data poin pelanggaran masih disimpan pada Arsip. Tujuan penelitian ini adalah merancang Website Sistem Poin Pelanggaran siswa pada SMA Negeri 10 Kota Ternate. Pengumpulan data dilakukan dengan cara wawancara, dan observasi. Tahap penelitian dimulai dari analisis sistem, kemudian analisis pengembangan sistem. Analisis sistem menggunakan Model Driven yang berorentasi objek, sedangkan pengembangannya menggunakan metode Prototyping. Sistem ini dirancang dengan alat bantu UML (Unified Modeling Language), bahasa pemrograman yang dgunakan adalah HTML, CSS, dan PHP, Database dibuat menggunakan MySQL. Hasil penelitian adalah website Poin Pelanggaran Siswa SMA Negeri 10 Kota Ternate yang memudahkan pihak sekolah pada proses pengelolahan data Poin Pelanggaran siswa. Sistem informasi data Poin Pelanggaran lebih efektif dan efesien sehingga orang tua dan siswa dapat melihat hasil laporan data pelanggaran tersebut dan mempermuda Guru BK dan Kesiswaan dalam mengolah data Poin Pelanggaran Siswa.
\end{abstract}

Kata Kunci: Perancangan Sistem Informasi, Data Poin Pelanggaran Siswa, Berbasis Website.

\section{Abstract}

The country' ten Ternate high School is located at Street Ki Hajar Dewantara, village office Takoma districts Kota Tengah. Student Violation Points at Ternate City High School ten are still recorded manually, and the violation points storage is still stored in the Archive. This study aimed to design a Website for the Students Violation Points System at Ternate ten Public High School. The collection is done by interview and observation. The research phase starts from system analysis, then analysis of system development. Analysis of the system uses a Model-Driven oriented object, while its development uses the Prototyping method. This system is designed with the UML (Unified Modeling Language) tool. The programming languages used are HTML, CSS, and PHP; the Database is created using MySQL. The study results were the Students Abuse Points ten Ternate City High School website, making it easy for the school to manage its Abuse Points. In addition, the information system of the Violation Points data is more effective and efficient so that parents and students can see the results of the violation data report and make the counselor and Student Teachers process processing the Student Violation Points. 


\section{Keywords: Design of Information System for Student Violation, Points Data, Based on}

Website

\section{PENDAHULUAN}

Pendidikan mempunyai peranan yang sangat penting dalam kehidupan manusia. Seiring dengan kemajuan ilmu pengetahuan dan teknologi, maka diperlukan guru yang profesional yang dapat melaksanakan tugasnya sebagai pendidik, pengajar, pembimbing dan pelatih anak-anak bangsa di masa depan yang dapat memberikan arah pembelajaran yang aktif, kreatif, inovatif serta minat yang tinggi pada peserta didik.

Peraturan Menteri Pendidikan Nasional Nomor 39 Tahun 2008 tentang Pembinaan Kesiswaan disebutkan bahwa untuk mengembangkan potensi siswa sesuai dengan fungsi dan tujuan pendidikan nasional, yaitu siswa yang beriman dan bertakwa kepada Tuhan Yang Maha Esa, berakhlak mulia, sehat, berilmu, cakap, kreatif, mandiri, dan menjadi warga negara yang demokratis serta bertanggung jawab, diperlukan pembinaan kesiswaan secara sistematis dan berkelanjutan. Dalam lampiran peraturan ini disebutkan bahwa salah satu contoh jenis kegiatan pembinaan kesiswaan adalah pembinaan budi pekerti luhur atau akhlak mulia yang antara lain berupa: (1) melaksanakan tata tertib dan kultur sekolah; (2) melaksanakan kegiatan $7 \mathrm{~K}$ (keamanan, kebersihan, ketertiban).

Seiring perkembangan pendidikan di tingkat SMA di indonesia mengalami beberapa permasalahan seperti tawuran. tawuran pada tingkat pelajar dikategorikan sebagai bentuk kenakalan remaja. Kenakalan remaja yang terjadi pada diri remaja sering kali kita temui dalam kehidupan sehari-hari. Salah satu sistem informasi yang dibutuhkan pada sekolah
SMA Negeri 10 kota Ternate saat ini yaitu sistem informasi mengenai data poin pelanggaran siswa. Sistem informasi ini sangat berpengaruh demi kelancaran proses peningkatan kualitas pendidikan. Sistem informasi data poin pelanggaran siswa juga dapat mempermudah pihak sekolah dalam melakukan pembuatan data poin pelanggaran siswa. Pelanggaran siswa yang tadinya masih dicatat manual dan proses penyimpanan data-data poin pelanggaran siswa masih disimpan pada arsip dan sehingga jika data-data tersebut hilang membutuhkan waktu dalam melakukan pencarian data poin pelanggaran. Maka dari itu peneliti mengusulkan "Sistem Informasi Data Poin Pelanggaran Siswa Menggunakan Metode Prototyping Berbasis Web Pada SMA Negeri 10 Kota Ternate" yang nantinya dapat membantu pihak sekolah dalam pembuatan laporan pelanggaran siswa.

\section{Rumusan Masalah}

Berdasarkan uraian latar belakang yang telah dikemukakan di atas, maka dapat dirumuskan, masalah penelitian ini. yaitu Bagaimana membangun sistem informasi data poin pelanggaran siswa berbasis web pada SMA Negeri 10 Kota Ternate?

\section{Tujuan Penelitian}

Adapun tujuan penelitian ini adalah:

1. Untuk membangun sistem informasi data poin pelanggaran siswa berbasis Web pada SMA Negeri 10 Kota Ternate.

2. Agar dapat membantu pihak sekolah terutama pada kesiswaan dalam mengelolah data poin pelanggaran siswa. 


\section{Manfaat Penelitian}

1. Untuk membantu mengurangi beban kinerja/pihak sekolah dalam menyelesaikan data-data pelanggaran siswa.

2. Mempermudah pihak sekolah untuk mengolah data poin pelanggaran bagi siswa secara lebih mudah dan efisien.

3. Mempermudah proses pencarian data poin pelanggaran siswa.

\section{Tinjauan Pustaka}

Penelitian yang dilakukan oleh Rizki Wahyudi, dan Aprilita Dwi Aristantia (2017) yang berjudul Pengolahan data pelanggaran siswa pada SMK Yayasan Pendidikan Teknologi 1 Purbalingga terintegrasi dengan sms Getway. Tujuan Penelitian ini bertujuan untuk mempermudah penanganan ketidakdisiplinan siswa dalam lingkungan sekolah dengan membangun aplikasi yang memermudah perhitungan point pelanggaran tata tertib siswa hingga pihak sekolah dapat melakukan tindakan dan kebijakan-kebijakan yang berkaitan dengan peningkatan kepribadian siswa serta dengan di integrasikannya aplikasi dengan sms gateway yang secara otomatis mengirimkan laporan tentang ketidakdisiplinan siswa langsung kepada wali murid.

Penelitian yang dilakukan oleh Ellen Ershinta Putri, Azis Ahmad (2015) yang berjudul Perancangan Sistem Informasi Poin Pelanggaran Dan Prestasi Siswa Berbasis Sms Gateway Pada Sekolah Menengah Kejuruan Negeri 3 Pacitan. Tujuan penilitian ini adalah membangun dan menghasilkan sistem informasi poin pelanggaran dan prestasi siswa berbasis sms gateway pada SMK Negeri 3 Pacitan.

\section{LANDASAN TEORI \\ Pengertian Sistem}

Menurut Romney dan Steinbart (2015:3), Sistem adalah rangkaian dari dua atau lebih dari komponen - komponen yang saling berhubungan, yang berinteraksi untuk mencapai suatu tujuan. Sebagian besar sistem terdiri dari sub sistem yang lebih kecil yang mendukung sistem yang lebih besar

Menurut Mulyadi (2016:5), Sistem adalah suatu jaringan prosedur yang dibuat menurut pola yang terpadu untuk melaksanakan kegiatan pokok suatu perusahan.

Berdasarkan definisi diatas maka dapat disimpulkan, bahwa sistem merupakan kumpulan dari beberapa himpunan elemen-elemen yang saling berinteraksi, memiliki keterkaitan dan saling bekerja sama serta membentuk suatu kesatuan untuk mencapai suatu tujuan atau sasaran tertentu.

\section{Pengertian Sistem Informasi}

Menurut Pratama (2014:15) sistem informasi (information system) merupakan gabungan bagian utama keempat tersebut meliputi perangkat lembut (perangkat lunak,perangkat keras, (perangkat terstruktur dan sumber daya manusia (SDM)

\section{Definisi Data Poin Pelanggaran Siswa}

Menurut Apriyani (2015:2), Data poin pelanggaran atau disebut fault point, berasal dari bahasa inggris yang dalam bahasa indonesia, dapat diartikan angka satu kesalahan atau pelanggaran yang dilakukan oleh seorang siswa yang bersangkutan, dimana terdapat rekapitulasi pelanggaran yang telah dilakukan. 


\section{Analisis Sistem}

Menurut Taufiq (2013:156), analisis Sistem adalah suatu kegiatan mempelajari sistem (baik sistem manual ataupun sistem yang sudah komputerisasi) secara keseluruhan mulai dari menganalisa sistem, analisa masalah, desain logic, dan memberikan keputusan dari hasil analisa tersebut.

\section{Pengembangan Sistem}

Muharto dan Ambarita (2016) Pengembangan sistem merupakan aktivitas untuk menghasilkan sistem informasi berbasis komputer untuk menyelesaikan persoalan (problem) organisasi atau memanfaatkan kesempatan (opportunities) yang timbul. Menyusun suatu sistem yang baru untuk menggantikan sistem yang lama secara keseluruhan atau memperbaiki sistem yang ada.

\section{Pengertian Prototyping}

Menurut Hasmoro dan Saufik (2014) Prototyping adalah sebuah versi dari suatu sistem potensial yang menyediakan pengembang dan user dengan suatu gambaran tentang bagaimana sistem dalam bentuk sempurnanya akan berfungsi.

\section{Pengertian Web Server}

Menurut Supono Putratama (2016:6) Web server adalah perangka lunak server yang berfungsi untuk menerrimah permintaan dalam bentuk situs web melalui HTTP atau HTTPS dari klien itu,yang di kenali sebagai Browser web dan mengirimkan kembali (reaksi) hasil dalam bentuk situsyang biasanya merupakan dokumen HTML

\section{Pengertian HyperText Markup Language(HTML)}

Menurut Solihin $(2016 ; 10), H T M L$ (Hyper Text Markup Language) adalah di kembangkan pertama kali oleh Tim Berners-Lee bersamaan dengan protokol HTTP (Hypertext Transfer Protocol) Tujuan utama pengembangan HTML adalah untuk menghubungkan setiap laman web dengan laman web lainnya.

\section{Pengertian Hypertext Processor (PHP)}

$$
\text { Menurut Solichin (2016:11) }
$$
mengemukakan bahwa PHP merupakan salah satu bahasa pemograman berbasis web yang di tulis untuk mengembang web dan $P H P$ sering digunakan pada sisi server sebuah web

\section{Pengertian Cascading Style Sheet (CSS)}

Menurut Arief (2013:323),CSS (Cascading Style Sheet) adalah suatu kode yang di maksudkan untuk mengatur tampilan web

Menurut Sibero (2013:112), menjelaskan bahwa CSS atau Cascanding Style Sheets adalah memiliki arti gaya menata halaman bertigkat, yang artinya setiap satu elemen yang telah di format dan di memiliki anak dan telah di format ,maka darielemen tersebut secara otomatis mengikuti format elemen induknya.

\section{Pengertian $X \boldsymbol{A M M P}$}

Menurut Pratama,I Putu Agus Eka (2014:440), Xampp merupakan Aplikasi web server bersifat instan (siap saji) yangdapat digunakan baik di sistem operasi linux maupun di sistem operasi Windows.

\section{Pengertian Unified Modeling Language (UML)}

Unified Modeling Language (UML) adalah salah satu standar bahasa yang banyak digunakan di dunia industri untuk 
mendefinisikan requirement, membuat analisis dan desain, serta menggambarkan arsitektur dalam pemrograman berorientasi objek. UML merupakan bahasa visual untuk pemodelan dan komunikasi mengenai sebuah sistem dengan menggunakan diagram dan teks-teks pendukung. $U M L$ muncul karena adanya kebutuhan pemodelan visual untuk menspesifikasikan, menggambarkan, membangun, dan dokumentasi dari sistem perangkat lunak $U M L$ hanya berfungsi untuk melakukan pemodelan. Jadi penggunaan $U M L$ tidak terbatas pada metodologi tertentu, meskipun pada kenyataannya $U M L$ paling banyak digunakan pada metodologi berorientasi objek (Rosa A.S dan M. Shalahudin 2014:133).

\section{Use Case Diagram}

Rosa dan M. Shalahudin (2014:155), use case atau diagram use case merupakan pemodelan untuk kelakuan (behavior) sistem informasi yang akan dibuat. Use case mendeskripsikan sebuah interaksi antara satu atau lebih aktor dengan sistem informasi yang akan dibuat. Secara kasar, use case digunakan untuk mengetahui fungsi apa saja yang ada di dalam sebuah sistem informasi dan siapa saja yang berhak menggunakan fungsi-fungsi itu.

\section{Sequence Diagram}

Rosa dan M. Shalahudin (2014:155) diagram sekuen menggambarkan kelakuan objek pada use case dengan mendeskripsikan waktu hidup objek dengan massage yang dikirimkan dan diterima antar objek. Oleh karena itu untuk menggambarkan diagram sekuen maka harus diketahui objek-objek .

\section{Metode Pengumpulan Data}

Metode pengumpulan data merupakan cara yang digunakan peneliti untuk mendapatkan data dengan cara wawancara, observasi dan dokumentasi. Yaitu dengan cara tatap muka dan tanya jawab langsung dengan salah satu pihak Sekolah guru bimbingan konseling, pada Sekolah SMA Negeri 10 Kota Ternate, melakukan Observasi megumpulkan data dan Studi Kepustakaan Dengan mencari dan mengumplkan data yang diperlukan dari berbagai Jurnal,jurnal, Karya Ilmih, Buku-buku, yang dapat menunjang dan menjadi referensi

\section{PERANCANGAN SISTEM Rancangan Tabel}

Tabel 1. admin

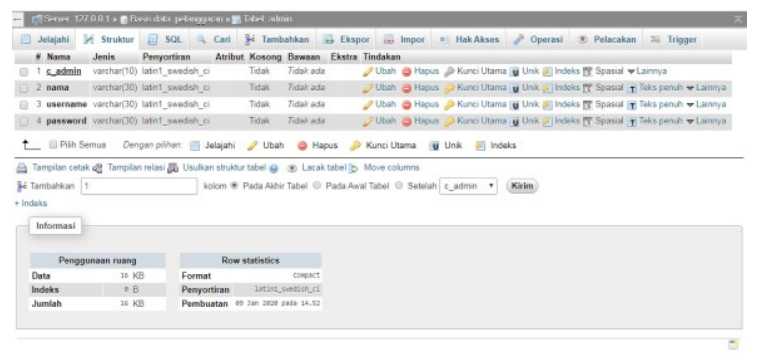

Tabel 2.bentuk pelanggaran

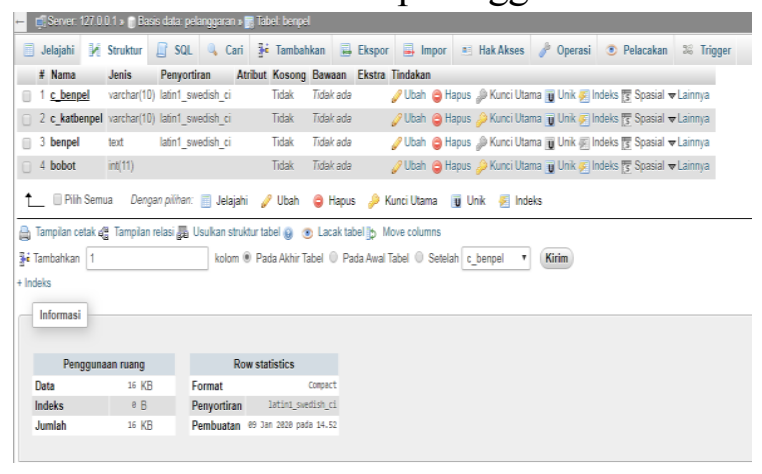

Tabel 3. tabel chat

\section{METODE PENELITIAN}




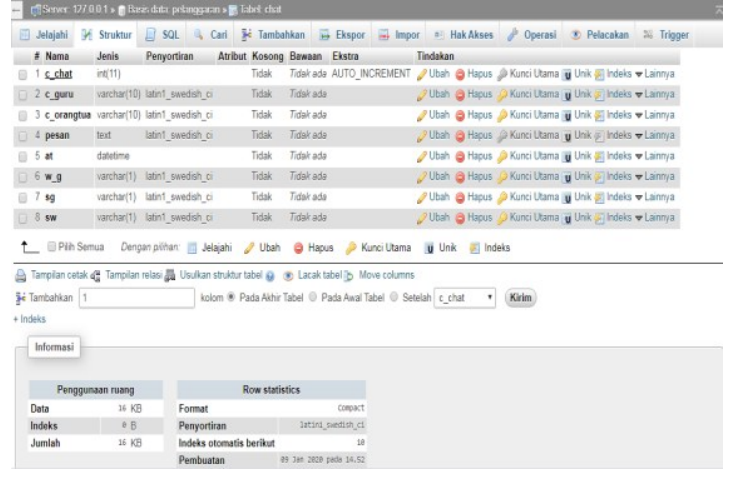

Tabel 4. tabel guru

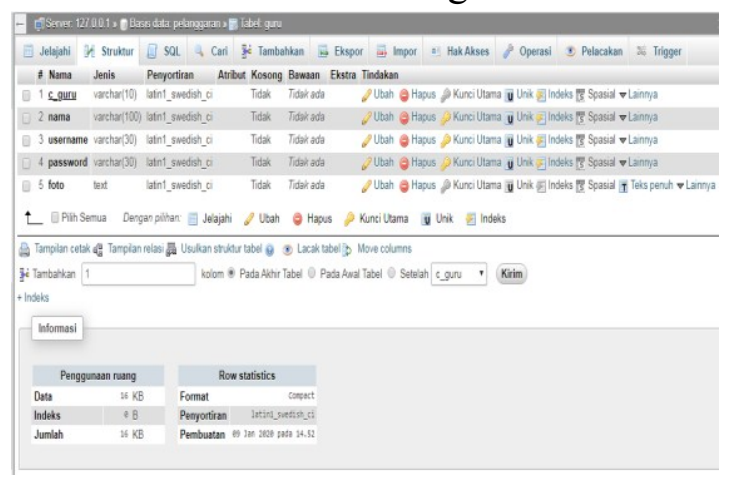

Tabel 5. tabel kategori pelanggaran

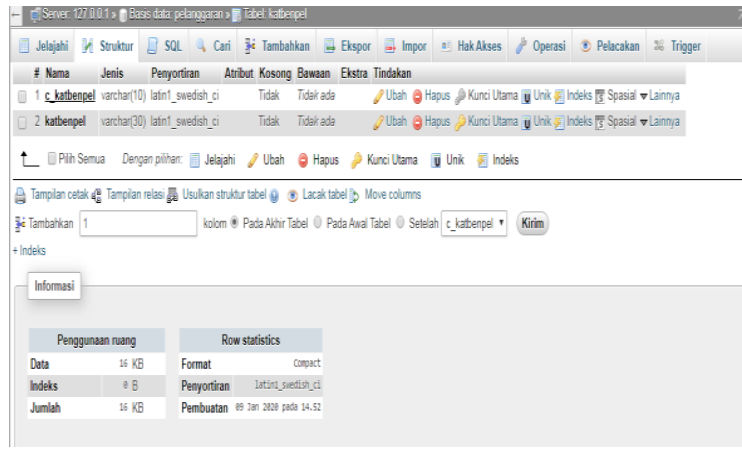

Tabel 6. tabel kelas

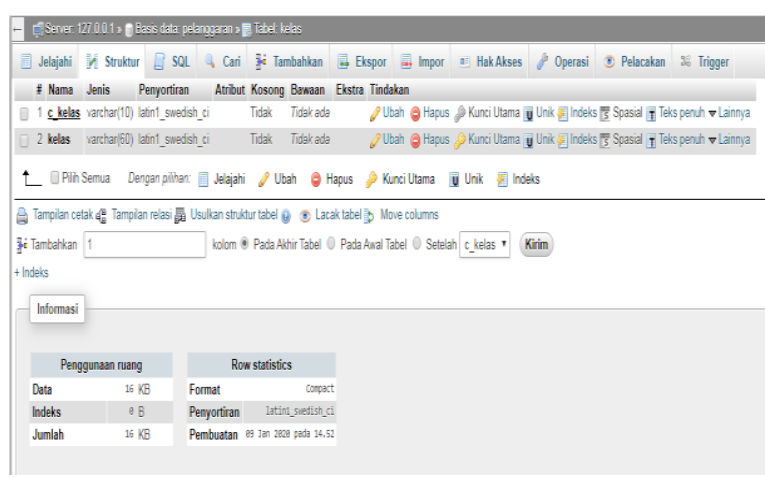

Tabel 7. tabel orang tua

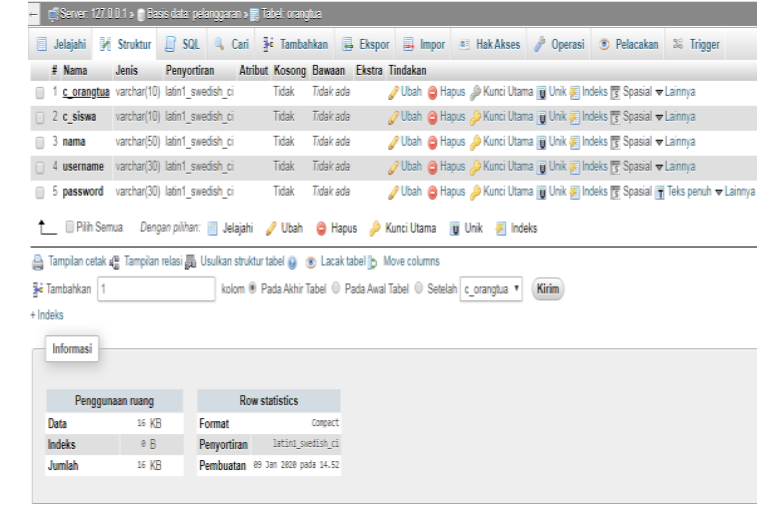

\section{Diagram Use Case}

Use case adalah rancangan awal sistem informasi dimana terdapat sistem dan actor yang merupakan fungsional yang berhubungan langsung dengan sistem. gambar Rancangan use case dapat di lihat berikut ini

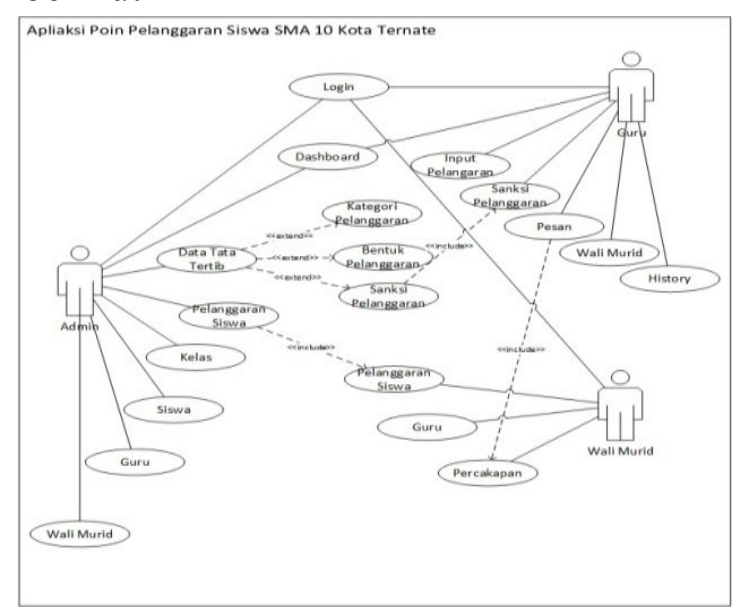

Gambar 1. Diagram Use Case

\section{Activity Login Admin,Guru,Wali Murid}

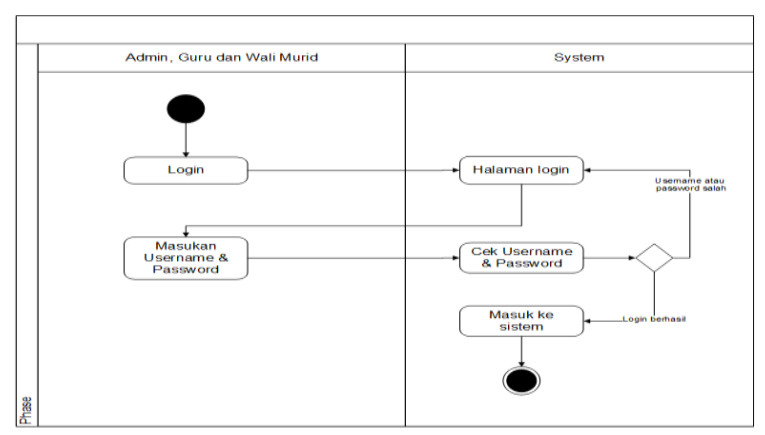

Gambar 2. Activity Login admin, guru, wali murid 


\section{Aktivity Admin Kelola Kategori Pelanggaran}

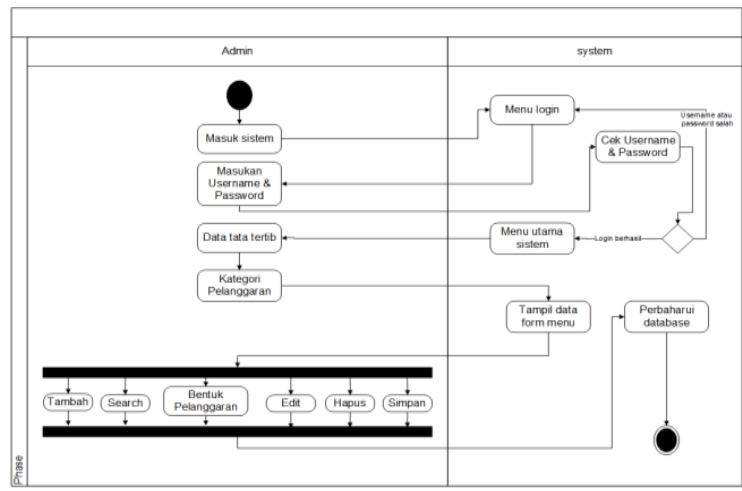

Gambar 3. Activity kelola kategori pelanggaran admi

\section{Aktivity Admin Kelola Bentuk Pelanggaran}

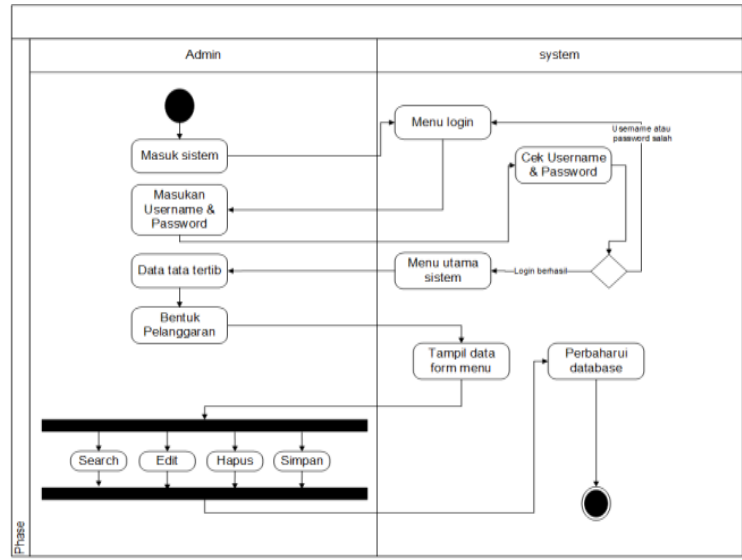

Gambar 4. Activity admin bentuk pelanggaran

\section{Aktivity Guru Kelola Pelanggaran Siswa}

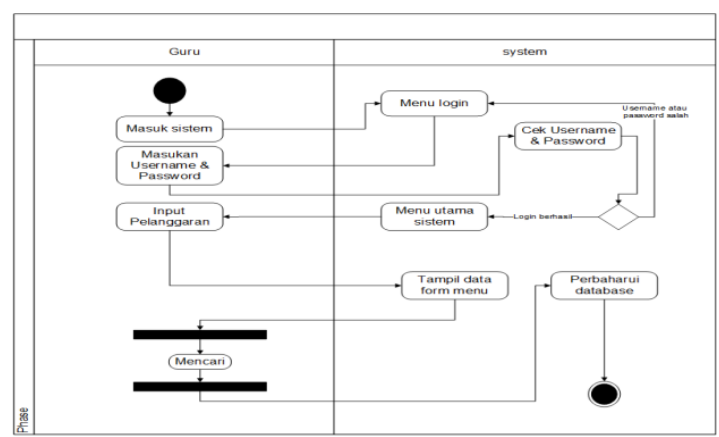

\section{Aktivity Guru Kelola Sanksi Pelanggaran}

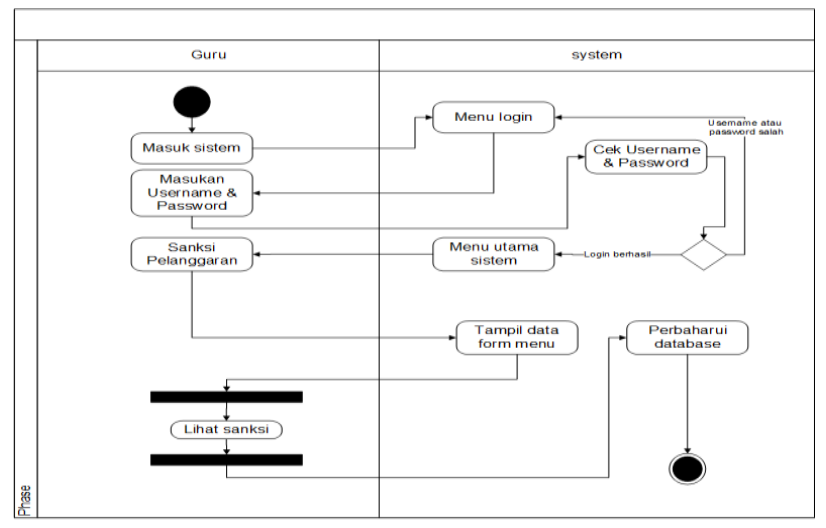

Gambar 4. Activity guru kelola sanksi pelanggaran

\section{Class Diagram}

Class diagram menggambarkan struktur statis class di dalam sistem. Class merepresentasikan sesuatu yang ditangani oleh sistem. dengan melihat karakteristik sistem data poin pelanggaran Siswa Berikut ini merupakan class diagram perancangan website sistem Poin Pelanggaran Siswa Pada SMA Negeri 10 Kota Ternate:
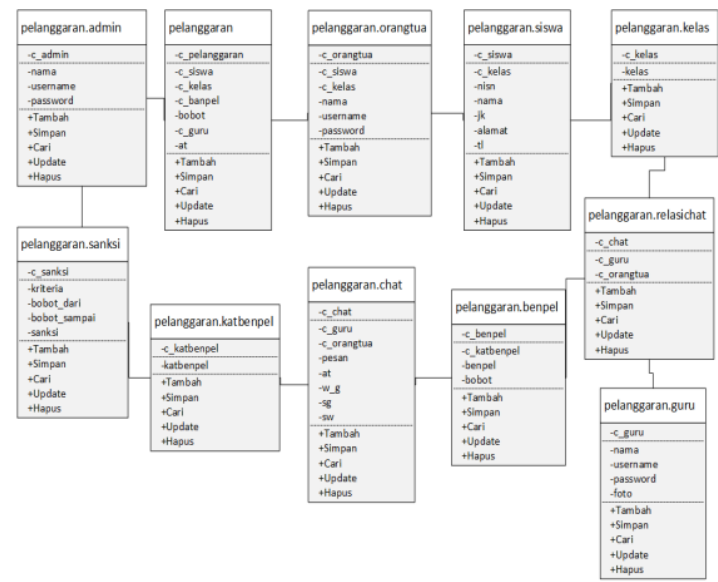

Gambar 5. class diagram

\section{IMPLEMENTASI DAN PENGUJIAN}

Halaman Login Admin

Gambar.3. Activity Admin Guru Kelola Pelanggaran Siswa 


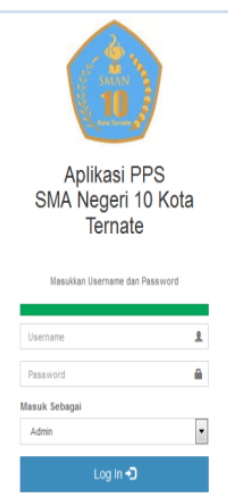

Gambar 6. Halaman login admin

\section{Halaman Menu Admin}

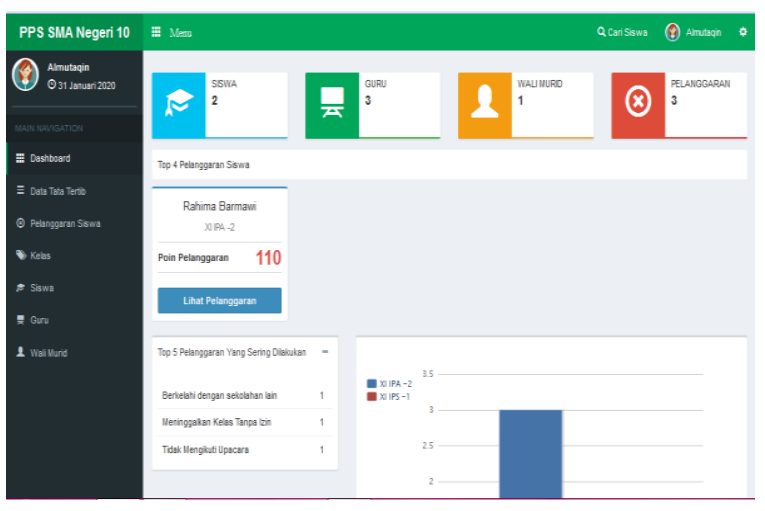

Gambar 7. Halaman Menu admin

\section{Halaman Admin Input Kategori}

\section{Pelanggaran}

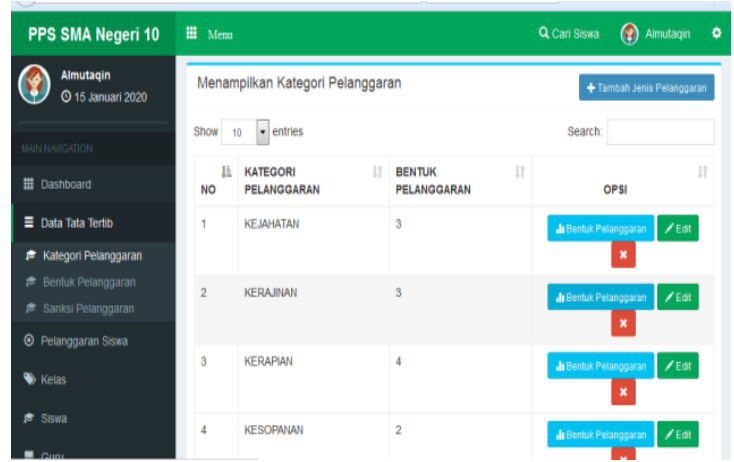

Gambar 8.admin input kategori pelanggaran

Halaman Admin Tambah Jenis Pelanggaran

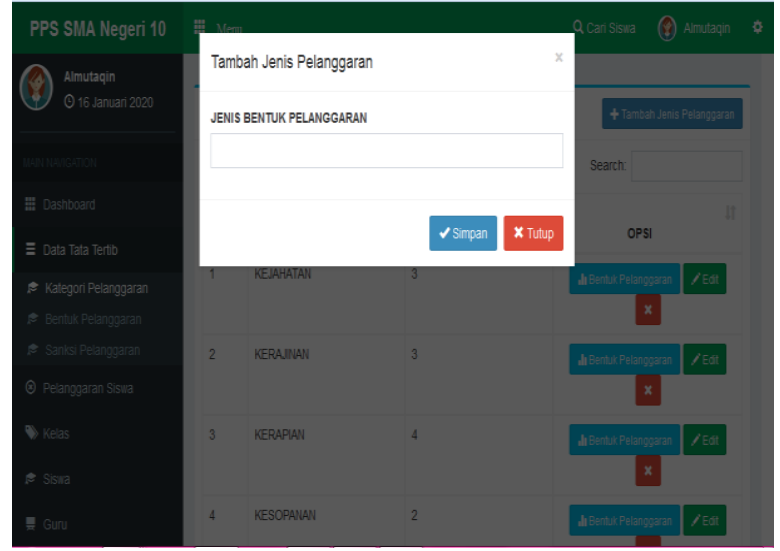

Gambar 9. Halaman admin tambah pelanggaran

\section{Halaman Admin Input Bentuk Pelanggaran}

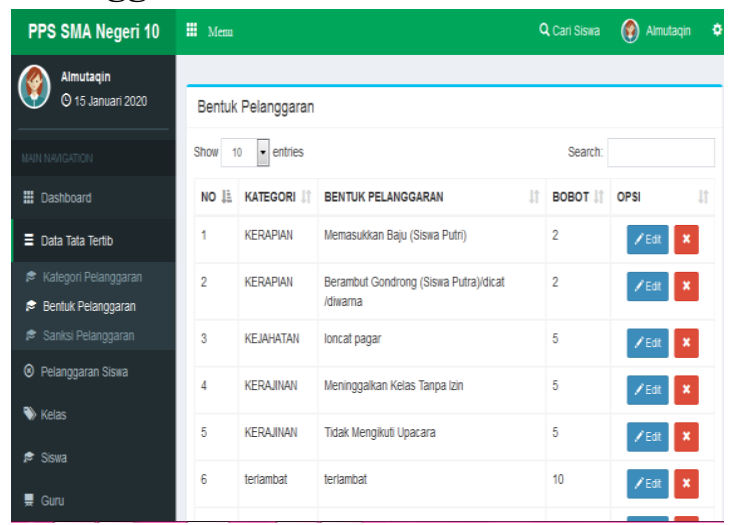

Gambar 10.admin Input bentuk pelanggaran

\section{Halaman Admin Input Sanksi \\ Pelanggaran}

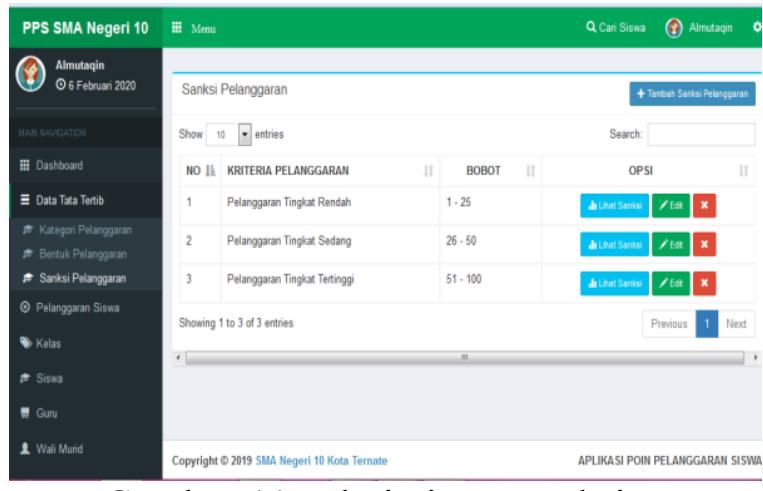

Gambar 11. admin input sanksi pelanggaran siswa

Halaman Admin Input Pelanggaran Siswa 


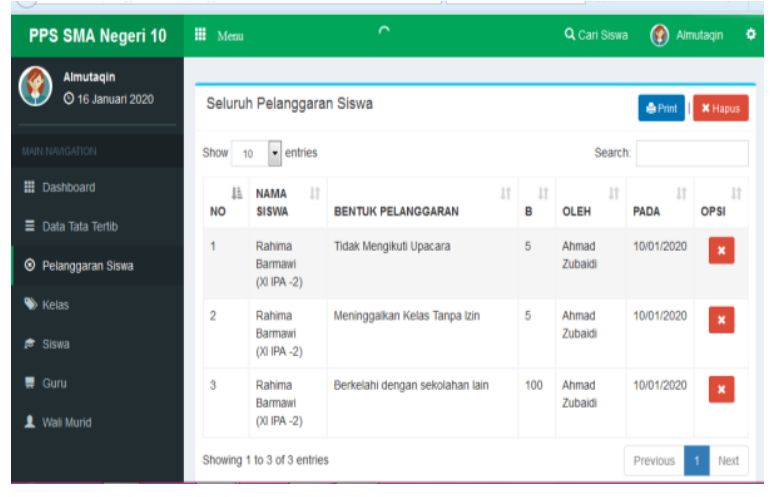

Gambar 12. Halaman admin input data pelanggaran siswa

\section{Halaman Admin Input Kelas}

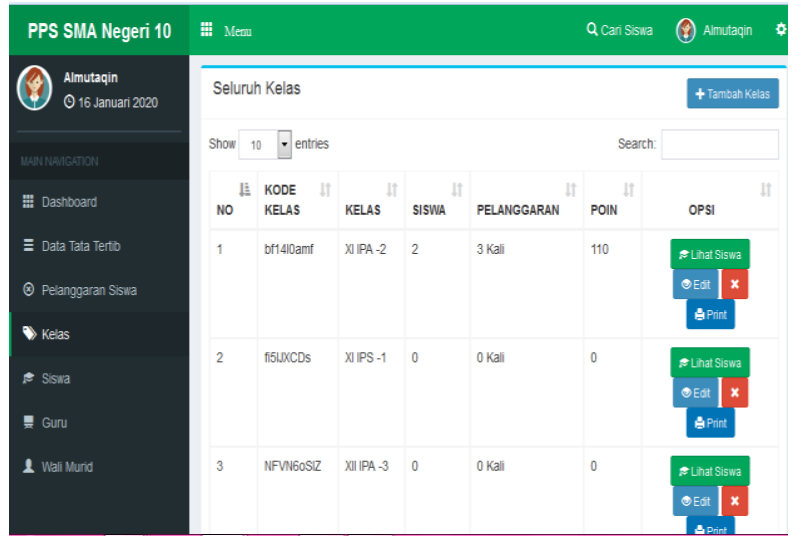

Gambar 13. admin input kelas

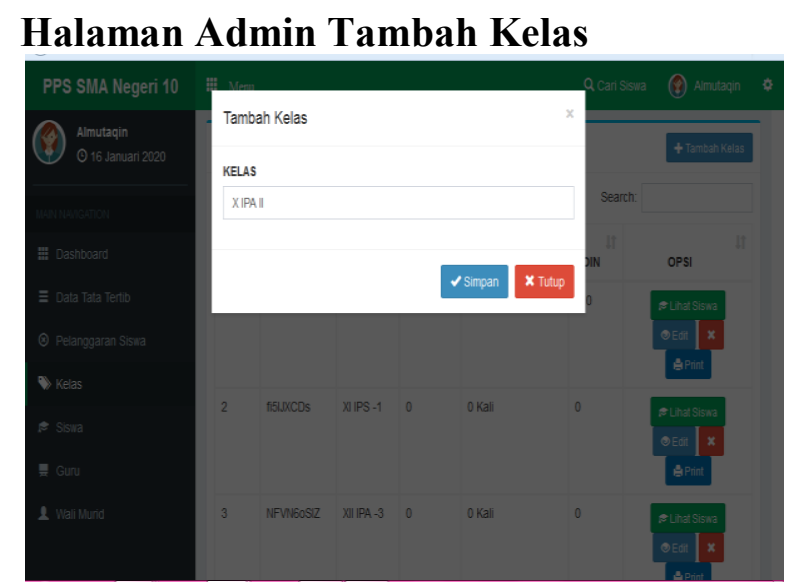

Gambar 14. Admin. tambah kelas

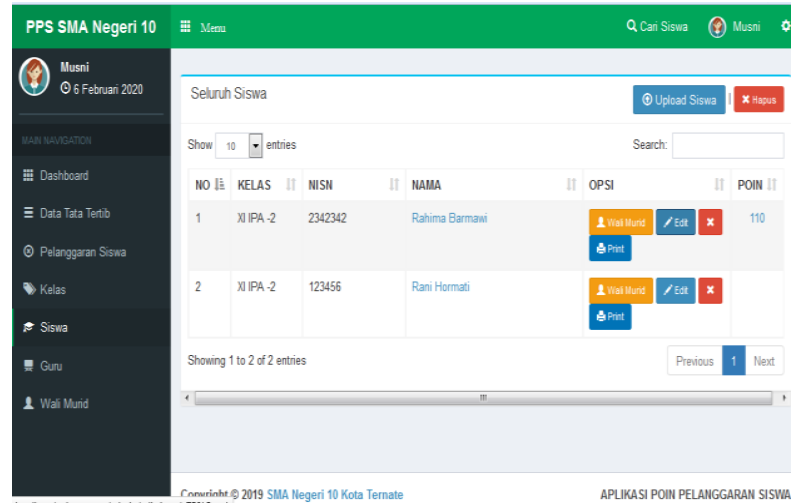

Gambar 15.admin. input data siswa

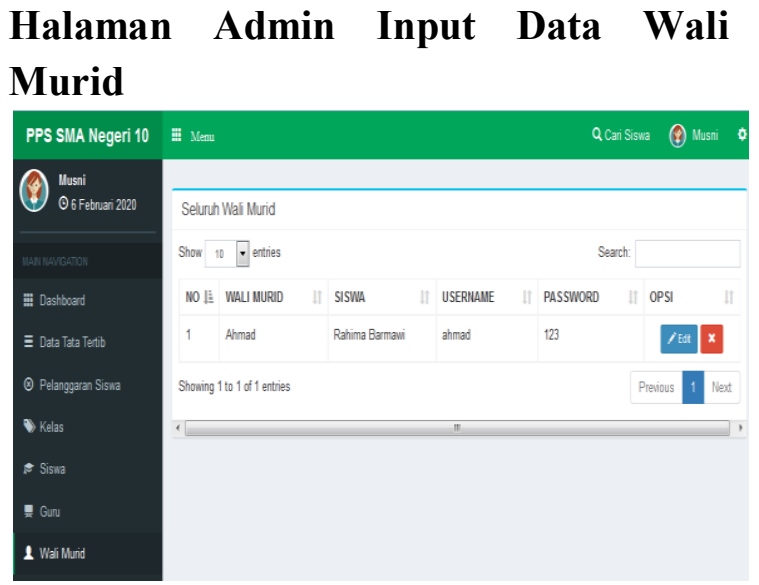

Gambar 16. admin data wali murid

\section{Halaman Admin Setting Wali Murid}

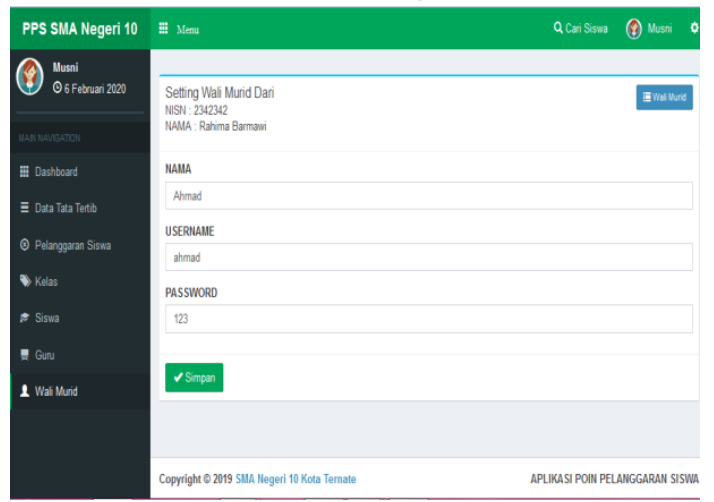

Gambar 17. Halaman admin Setting wali murid

\section{Halaman Menu Guru}

Halaman Admin Input Siswa 


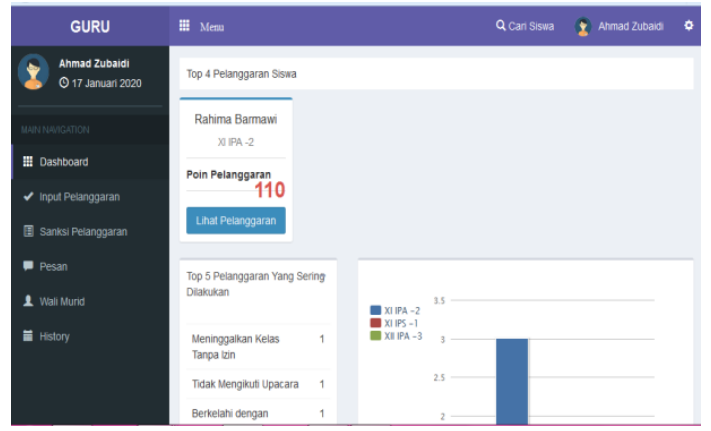

Gambar 18. Halaman menu guru

\section{KESIMPULAN}

Berdasarkan hasil penelitian yang dilakukan penulis mengenai sistem informasi Data Poin Pelanggaran di SMA Negeri 10 Kota Ternate berbasis web dapat ditarik kesempulan sebagai berikut:

1. Sistem informasi data poin pelanggaran siswa lebih mempermuda kesiwaan dan guru dalam pengawasan siswa yang melakukan pelanggaran.

2. Perancangan dan implementasi yang meliputi proses pengolahan data poin pelanggaran, data sanksi pelangaran, data kelas, data siswa data guru, dan data wali murid.

3. Aplikasi data poin pelanggaran berbasis web ini sudah menggunakan percakapan untuk berkomunikasi antara guru dan wali murid, Ketika siswa membuat pelanggaran guru maka dapat mengirim pesan ke wali murid.

\section{Saran}

Sistem informasi Poin Pelanggaran ini tentunya tidak terlepas dari kekuranagan dan kelemahan, Oleh karena itu penulis menyarankan hal-hal berikut :

1. Sistem poin pelanggaran ini belum menampilkan Riwayat siswa yang melakukan pelanggaran, sehingga perlu menambahkan

2. Pada sistem informasi pada poin pelanggaran siswa di harapkan dapat di jalankan agar bermanfaat bagi semua pihak yang terkait baik dari pihak sekolah, siswa, maupun orang tua.

\section{DAFTAR PUSTAKA}

Ardhana, YM Kusuma. (2013), Pemrograman PHP CodeIgniter Blackbox, Jasakom, Jakarta

Apriyani, (2015), Perkembangan dan Analisis Kualitas Sistem Pengelolaan Poin Pelanggaran Tata Tertib Siswa Berbasis Web di SMK Muhammadiyah 1 Bantul, Skripsi, Fakultas Teknik, Universitas Negeri Yogyakarta: Yogyakarta.

Asropudin, P. (2013), Kamus Teknologi Informasi. Bandung: Titian Ilmu.

Buana, I Komang. S. (2014),Jago Pemrograman PHP. Yogyakarta: Penerbit Dunia Komputer.

Dondeti, Jagruthi dan Nidhra, Srinivas. (2013), Black Box And White Box Testing Techniques-A Literature Review, International Journal of Embedded Systems and Applications (IJESA) Vol. 2, No. 2, pp 8-9.

Hartono, B. (2013), Sistem Informasi Manajemen Berbasis Komputer. Jakarta. RinekaCipta.

Jogiyanto. (2013), Analisis \& Desain Sistem Informasi :Pendekatan tertruktur teori dan praktik aplikasi bisnis. Yogyakarta. Andi Offset.

Rosa \& Shalahuddin, M. (2013), Rekayasa Perangkat Lunak Terstruktur Dan Berorientasi Objek. Bandung. Informatika.

Saputra, A. (2013), Membangun Aplikasi Bioskop dan SMS untuk Panduan Skripsi,. Jakarta, PT Elex Media Komputindo

Sibero, A. F.K. (2013), Web Programming Power Pack. Yogyakarta: Mediakom

Sukamto, R,A. Shalahuddin,M., (2014), Modul Pembelajaran Rekayasa Perangkat Lunak, Bandung. 
Taufiq, R. (2013), Sistem Informasi Manajemen. Konsep Dasar, AnalisisdanMetodePengembangan. Yogyakarta: GrahaIlmu.

Ladjamudin, Bin Al-bahra (2013), Analisis dan desain Sistem Informasi. Yogyakarta: Graha Ilmu.

Farida Hanum. (2014), Pengembangan kultur Akademik Siswa Sekolah Menegah Pertama 3 Jetis Bantul. Jurnal Penelitian. FIP UNY.

Kadir, Abdul (2014), Pengenalan Sistem Informasi edisi Revisi. Yogyakarta: Penerbit ANDI.

Hidayatullah,Priyanto dan Jauhati Khairl K.(2015), Pemograman Web. Bandung: Informatika Bandung.

Pratama, I Putra Agus Eka. (2014), Sistem Informasi dan implementasinya. Bandung: Informatika Bandung

Hidayatullah P, Kawistara, Jk (2014) Pemograman. Bandung: Informatika Bandung

Achmad Solihin, (2016), Pemograman Web dengan PHP dan MYSQL, Penerbit Budi Luhur.

Winarno, Edy: AliZaki, SmithDev, (2014), Pemograman web berbasis HTMLS, PHP, dan Javascript. PT Elex Media Komputindo. Jakarta

Hidayat, Dapai Ari, (2014), Rancangan Bangunan Aplikasi Point Of Sace (Pos) Berbasis web dengan Ipemanfaatan Trugger pada Distribution store CVNMRQ. Jurnal sistem dan Teknologi Informasi (Justin). Vol.2,No-1. 